\title{
Vapor pressures of phenolic compounds found in pyrolysis oil
}

\author{
Parsa Mozaffari, Zachariah Steven Baird, Oliver Järvik ${ }^{l}$ \\ Tallinn University of Technology, School of Engineering, Department of Energy Technology, \\ Ehitajate tee 5, 19086 Tallinn, Estonia
}

\begin{abstract}
Oil produced from pyrolysis of Kukersite oil shale and lignocellulosic biomass both contain significant amounts of phenolic compounds. Here we present new experimental vapor pressure data for two such compounds (4-ethyl-2-methoxyphenol and 5-methylresorcinol) and also for a mixture of phenolic compounds extracted from pyrolysis oil (Honeyol ${ }^{\mathrm{TM}}$ ). Vapor pressure data was measured by high pressure differential scanning calorimetry (DSC), in accordance with the ASTM E 1782 standard test method. The measurements were conducted in the pressure range from $0.89 \mathrm{kPa}$ to atmospheric pressure. The measured temperature ranges for the vapor pressure were 374.5 to $509.1 \mathrm{~K}$ for 4-ethyl-2-methoxyphenol, 428.0 to $565.0 \mathrm{~K}$ for Honeyol $^{\mathrm{TM}}$ and 429.4 to $565.8 \mathrm{~K}$ for 5-methylresorcinol. Density data for 4-ethyl-2methoxyphenol were also measured at 293.15 to $363.15 \mathrm{~K}$. The experimental vapor pressure and density data for 4-ethyl-2-methoxyphenol were fitted using the PC-SAFT equation of state, and the vapor pressure data for the other compounds was fit using the Antoine equation. Enthalpies of vaporization were also calculated. The properties of these compounds were then compared to literature data for other pure phenolic compounds and mixtures of the phenolic compounds from Kukersite shale oil. This comparison indicates that some pure compounds, such as 4-ethyl-2-methoxyphenol, could be used as model compounds for estimating the properties of the phenolic portion of pyrolysis oil.
\end{abstract}

Keywords: Differential scanning calorimetry (DSC), Vapor pressure, density, PC-SAFT, 5Methylresorcinol, Honeyol ${ }^{\mathrm{TM}}$, 4-Ethyl-2-methoxyphenol

\section{Introduction}

Continuous fossil fuel production to meet worldwide energy demands has led to large emissions of greenhouse gases, and climate change resulting from this has spurred interest in producing fuels from biomass. Some countries continue to show interest in using their local oil shale resources, even though it is a fossil fuel, as a way to ensure domestic energy security. Hence, renewable energy resources as well as unconventional energy resources, such as oil produced from oil shale or wastes such as plastics and tires, have drawn substantial attention in the past decades [1]. Oil shale is an organic rich sedimentary rock from which oil is produced

\footnotetext{
${ }^{1}$ Email addresses: zachariah.baird at taltech.ee, oliver.jarvik at taltech.ee, parsa.mozaffari at taltech.ee
} 
through pyrolysis. The main organic component of oil shale is an insoluble solid macromolecular structure called kerogen [2]-[6]. The properties of the shale oil produced vary depending on the type of kerogen (i.e. oil shale) and the conversion process used. Therefore, the concentration of phenolic compounds in shale oil varies. In shale oil produced from Kukersite oil shale there is a high concentration of phenolic compounds [6]. Although shale oil has not seen widespread commercial use, it is an important fuel in some regions, such as Estonia, Brazil, and China [7].

Alternatively, biomass can also be converted to bio-oil through pyrolysis [8], [9]. Generally plant biomass is used, the major components of which are lignin, hemicellulose and cellulose. Because such lignocellulosic biomass contains large amounts of oxygen, the resulting bio-oil also generally contains many oxygenated compounds. Lignin often decomposes into phenolic compounds, and these can be utilised to produce fine phenolic chemicals [10]. Furthermore, because the lignin in biomass contains aromatic structures, it is an important element for replacement of petroleum crude oil with biomass [11], [12].

Additionally, these phenolic compounds can be valuable chemicals and are often less desirable in fuel due to problems with thermal instability, chemical instability and hydrocarbon immiscibility [13], [14], [15]. Therefore, information on their properties can also be useful for designing systems to separate or convert these phenols (such as hydrodeoxygenation).

Phenolic compounds from shale oil and bio-oil are used by various industries. For example, water-soluble phenols are extracted from shale oil, fractionated, and crystallized to yield products for chemical industries [16] [17]. These water-soluble compounds are mainly a mixture of alkylresorcinols, and 5-methylresorcinol is the primary component. Pure 5methylresorcinol is used as a raw material to synthetize cosmetic dyes, fungicides, drugs, etc. or as reagent for analytical chemistry [18] [17]. Honeyol ${ }^{\mathrm{TM}}$ - a mixture of resorcinols produced and sold by Viru Keemia Grupp (VKG) - contains approximately 60\% 5-methylresorcinol. This product is of interest to various industries and is used as a substitute for resorcinol and phenols in the rubber, wood processing, construction, and oil industries. Compared with resorcinol, the alkyl substituent in the alkylresorcinol molecular structure improves resin adhesion as well as heat and water resistance.

Vaporization properties of oil and oil products, including phenolic compounds, are important for production, storage, transportation, and environmental risk assessment. [19]-[21]. Therefore, modelling the volatility characteristic of oil compounds in a simple form is crucial to characterizing their thermodynamic behavior. One possible approach to estimate such vaporization parameters is to utilize pure compounds, or compounds derived from oil with 
similar characteristics, as pseudocomponents. [22] However, the data regarding thermodynamic properties of phenolic compounds are scarce. Existing correlations are not sufficient to model the thermodynamic and physical properties of phenolic compounds, so new experimental data on their properties are critical to produce and handle these compounds.

Therefore, in this work, three phenolic compounds that are often present in pyrolysis oil were chosen for vapor pressure measurements. 4-ethyl-2-methoxyphenol (4-ethylguaiacol) was selected as a lignin derived phenolic monomer. This compound is widely used as a chemical intermediate for preparation of polymers, medicines, resins, and pesticides and is also produced from petroleum sources. As a replacement for fossil fuel utilization, this compound can also be produced from a renewable source, lignin, which is noticeably more environmentally favourable [12]. Among the compounds studied here, the only available literature data was for 5-methylresorcinol in the work by Da Silva and Ferreira in which the vapor pressure of 5methylresorcinol was measured in the temperare range of 322.2-338.1 K [23].

Honeyol $^{\mathrm{TM}}$ and 5-methylresorcinol were selected as alkylresorcinols derived from Kukersite shale oil. The vapor pressures of these compounds were measured using a high pressure differential scanning calorimeter. Additional information regarding the application of DSC for measuring vapor pressures is provided in references [24]-[26].

\section{Experimental and Methods}

\subsection{Chemicals}

The phenolic compounds used in this work are 4-ethyl-2-methoxyphenol (CAS RN: 3360-416; $\mathrm{C}_{9} \mathrm{H}_{12} \mathrm{O}_{2}$ ), Honeyol ${ }^{\mathrm{TM}}$ and anhydrous 5-methylresorcinol (CAS RN: 504-15-4; $\mathrm{C}_{7} \mathrm{H}_{8} \mathrm{O}_{2}$ ). 4ethyl-2-methoxyphenol was purchased from ACROS Organics with a reported minimum purity of $98 \%$. Honeyol $^{\mathrm{TM}}$ and 5-methylresorcinol were provided by Viru Keemia Grupp (VKG). All the compounds in this study were used as received without further purification. Information about the compounds (Molecular weight, CAS RN, and empirical formula) are provided in Table 1. The compound suppliers and purity verified by gas chromatography (GC) are provided in Table 2. Honeyol ${ }^{\mathrm{TM}}$ composition analyzed by GCMS is given in Table 3. The chemical structures of the compounds are also presented in Figure 1. 
Table 1. The molecular weight, respective CAS number and empirical formulas of phenolic compounds studied.

\begin{tabular}{cccc}
\hline Compound & MW $(\mathbf{g} / \mathbf{m o l})$ & CAS RN & Empirical formula \\
\hline 4-ethyl-2-methoxyphenol & 152.2 & $3360-41-6$ & $\mathrm{C}_{9} \mathrm{H}_{12} \mathrm{O}_{2}$ \\
5-methylresorcinol & 124.1 & $504-15-4$ & $\mathrm{C}_{7} \mathrm{H}_{8} \mathrm{O}_{2}$ \\
Honeyol $^{\mathrm{TM}}$ & 143 & $799275-41-5$ & - \\
\hline
\end{tabular}

Table 2: Suppliers and measured purities of compounds used in this work

\begin{tabular}{cccc}
\hline Compound & Supplier & Analytical method & Purity $^{\mathbf{a}}$ \\
\hline 4-ethyl-2-methoxyphenol & ACRO Organics & GC & $98.6 \%$ \\
5-methylresorcinol & VKG & GC & $99.9 \%$ \\
Honeyol $^{\text {TM }}$ & VKG & - & - \\
\hline
\end{tabular}

${ }^{a}$ purity given as mass percent

Table 3: Honeyol ${ }^{T M}$ compositions measured by GC
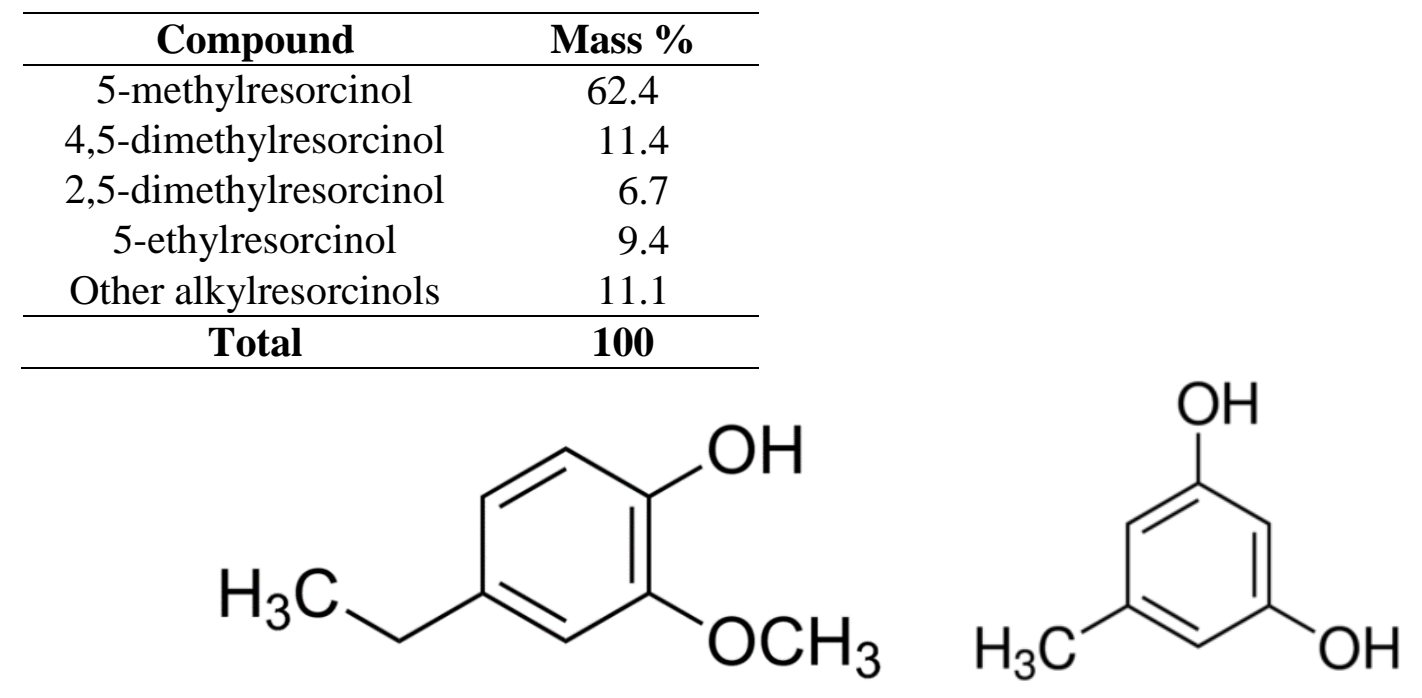

Figure 1. Chemical structures of phenolic compounds studied. (Left to right: 4-ethyl-2-methoxyphenol, Honeyol $^{T M}$, and 5-methylresorcinol). 
The experimental vapor pressure was measured within the range from $0.89 \mathrm{kPa}$ to atmospheric pressure. Corresponding temperature ranges were $428.1 \mathrm{~K}$ to $565.1 \mathrm{~K}$ for Honeyol $^{\mathrm{TM}}$, $429.4 \mathrm{~K}$ to $565.8 \mathrm{~K}$ for 5-methylresorcinol and $371.4 \mathrm{~K}$ to $509.1 \mathrm{~K}$ for 4-ethyl-2-methoxyphenol.

\subsection{Apparatus}

Vapor pressure measurements were carried out using a Netzsch 204HP Phoenix high-pressure differential scanning calorimeter (DSC), in accordance with standard test method ASTM E 1782 "Standard test method for determining vapor pressure by thermal analysis" [27].

The density of 4-ethyl-2-methoxyphenol was measured using a DMA 5000M density meter (Anton Paar $\mathrm{GmbH}$ ) from 20 to $90{ }^{\circ} \mathrm{C}$. The expanded uncertainty of the instrument is $0.00005 \mathrm{~g} / \mathrm{cm}^{3}$. When taking into account the purity of the 4-ethyl-2-methoxyphenol, the expanded uncertainty $(\mathrm{k}=2)$ was estimated to be $0.001 \mathrm{~g} / \mathrm{cm}^{3}$.

The molecular weight of Honeyol ${ }^{\mathrm{TM}}$ was measured by vapor pressure osmometric (VPO) using a Knauer K-7000 vapor pressure osmometer (Wissenschaftliche Gerätebau Dr. Ing. Herbert KNAUER GmbH, Germany). In this technique, distilled water was used as the solvent for measurement and an aqueous solution of $\mathrm{NaCl}$ with a molality of $433.8 \mathrm{mmol}\left(\mathrm{Na}^{+}+\mathrm{Cl}^{-}\right.$ )$/ \mathrm{kgH}_{2} \mathrm{O}$ was used as the calibration standard. The measurement was performed at $60{ }^{\circ} \mathrm{C}$. The accuracy of this method was thoroughly described earlier by Järvik and Oja [28]. The expanded uncertainty $(\mathrm{k}=2)$ was $\pm 6-7 \%$.

\subsection{Calibration}

Temperature calibration of DSC was performed at atmospheric conditions with tin $\left(\mathrm{T}_{\mathrm{m}}=231.9\right.$ $\left.{ }^{\circ} \mathrm{C}\right)$, indium $\left(\mathrm{T}_{\mathrm{m}}=156.6{ }^{\circ} \mathrm{C}\right)$, zinc $\left(\mathrm{T}_{\mathrm{m}}=419.6{ }^{\circ} \mathrm{C}\right)$, bismuth $\left(\mathrm{T}_{\mathrm{m}}=271.4^{\circ} \mathrm{C}\right)$, and lead $\left(\mathrm{T}_{\mathrm{m}}=327.5\right.$

$\left.{ }^{\circ} \mathrm{C}\right)$ standards. The calibration measurement procedure is similar to that used for the studied compounds, except that for metals a larger sample mass was used (10 to $15 \mathrm{mg}$ ). The vacuum sensor (MKS Baratron 626B) with a reported full-scale error of $0.008 \%$ was calibrated at Metrosert AS metrological centre which is traceable to Finnish VTT Mikes measurement pressure standard and CMI (Czech metrology centre) measurement pressure standard. The vacuum sensor's operating range was $0.0133-130 \mathrm{kPa}$ and the accuracy of the reading is $0.25 \%$ for measurements below atmospheric pressure. The distance between the outlet pressure sensors and DSC cell was measured to be $47 \mathrm{~cm}$, and therefore, the pressure drop at atmospheric 
conditions between the sensor and the measurement chamber was estimated to be $0.003 \mathrm{kPa}$. [29]

\subsection{Procedure}

The experimental procedure was thoroughly described in earlier articles from our research group by Siitsman et al. [21], [29], [30].

Sample mass was weighed on a micro-analytical balance (Sartorius Cubis Micro Balances $6.6 \mathrm{~S}$ ) with $\pm 0.001 \mathrm{mg}$ precision. For the measurements, a sample mass between 1-4 $\mathrm{mg}$ (or 1$4 \mu \mathrm{l}$ ) was used for experiments above $5 \mathrm{kPa}$. While, 4-9 mg (or 4-9 $\mu \mathrm{l}$ ) was used for experiments below $5 \mathrm{kPa}$ to prevent mass depletion during preboiling.

$40 \mu \mathrm{l}$ aluminium crucibles and lids with different pinhole diameters were used. The heating rate was $5 \mathrm{~K} / \mathrm{min}$. For measurement above $5 \mathrm{kPa}$, lids with $50 \mu \mathrm{m}$ laser drilled pinholes were cold welded to the crucibles using a sealing press and placed inside the DSC furnace. However, for experiments below $5 \mathrm{kPa}$, a $180 \mu \mathrm{m}$ micro drill was used to make the pinholes to avoid selfpressurization, and therefore, peak broadening which lowers the accuracy of onset temperature analysis [31]. Butrow and Seyler [32] suggested earlier that using larger pinholes from $175 \mu \mathrm{m}$ up to $375 \mu \mathrm{m}$ for vapor pressure measurements below $5 \mathrm{kPa}$, improves measurement accuracy to the point at which it is comparable to that of experimental values above $5 \mathrm{kPa}$.

For the present study, the DSC performance was validated using water and biphenyl (CAS 9252-4, purchased from Alfa Aesar Company, GC-analysed purity of $>99 \%$ ). The biphenyl was measured within the pressure range of $0.89 \mathrm{kPa}$ to atmospheric pressure and the boiling temperature of water was measured from $50 \mathrm{kPa}$ to atmospheric pressure. Comparison between biphenyl experimental results and literature values are given in Table 4. For distilled water, the obtained values were compared with the IAPWS95 equations of state [33] which is implemented in CoolProp [34]. The measured and reference values are given in Table 5. 
Table 4. Comparison of biphenyl literature data with experimental vapor pressure data

\begin{tabular}{|c|c|c|c|c|c|c|c|}
\hline $\mathbf{T}[\mathbf{K}]$ & $P[\mathrm{kPa}]$ & $\begin{array}{c}\text { Pref }_{\text {[kPa] }} \\
\text { ref.[35] }\end{array}$ & $\Delta \mathbf{P}[\%]^{\mathrm{a}}$ & $\begin{array}{l}\text { Pref }[\mathbf{k P a}] \\
\text { Ref. }[36]\end{array}$ & $\Delta \mathbf{P}[\%]^{\mathbf{a}}$ & $\begin{array}{c}\text { Pref }_{\text {[kPa] }} \\
\text { ref. [37] }\end{array}$ & $\Delta \mathbf{P}[\%]^{\mathrm{a}}$ \\
\hline 382.7 & 0.90 & 0.88 & 2.60 & & & & \\
\hline 409.4 & 2.89 & 2.87 & 0.75 & & & & \\
\hline 422.7 & 4.88 & 4.86 & 0.41 & & & & \\
\hline 442.7 & 9.95 & 9.87 & 0.76 & 10.02 & 0.74 & 9.87 & $-0.76 \%$ \\
\hline 478.9 & 29.88 & 29.89 & 0.05 & 30.03 & 0.52 & 29.89 & $0.05 \%$ \\
\hline 498.2 & 49.87 & 49.89 & 0.04 & 50.00 & 0.26 & 49.89 & $0.04 \%$ \\
\hline 527.8 & 100.40 & 100.02 & 0.38 & 100.15 & 0.24 & 100.02 & $-0.38 \%$ \\
\hline
\end{tabular}

${ }^{\mathrm{a}} \Delta p \%=\frac{P_{e}-P_{l i t}}{P_{e}} \times 100$

Table 5. Deviation of experimental values of water vapor pressure from the IAPWS95 equation of state [33].

\begin{tabular}{cccc}
\hline $\mathbf{P}[\mathbf{k P a}]$ & $\mathbf{T}[\mathbf{K}]$ & $\begin{array}{c}\mathbf{T}[\mathbf{k}] \\
\text { ref. [33] }\end{array}$ & $\boldsymbol{\Delta \mathbf { T } [ \% ] ^ { \mathbf { a } }}$ \\
\hline 49.8 & 354.4 & 354.4 & $0.0 \%$ \\
59.9 & 359.1 & 359.0 & $0.0 \%$ \\
69.9 & 363.0 & 363.0 & $0.0 \%$ \\
79.9 & 366.7 & 366.6 & $0.0 \%$ \\
100.9 & 373.4 & 373.0 & $-0.1 \%$ \\
\hline
\end{tabular}

${ }^{a} \Delta T \%=\frac{T_{e}-T_{\text {lit }}}{T_{e}} \times 100$

The vapor pressure of biphenyl has been previously studied for liquid [35]-[38] and solid phases [38]-[40]. A deviation plot of experimental DSC values is also presented in Figure 2. It was observed that DSC vapor pressure values are in excellent agreement with Chirico et. al [35] Chipman and Peltier [36] and Garrick and Gray [37]. Compared to those measured by Chirico et. al ( $350 \mathrm{~K}$ to $578 \mathrm{~K}$ ) [35], our experimental values deviate by a mere $0.07 \mathrm{kPa}$ for sub-atmospheric pressures and slightly less than $0.4 \mathrm{kPa}$ for atmospheric pressure. Chipman and Peltier [36] reported the vapor pressure from $436 \mathrm{~K}$ to $595 \mathrm{~K}$ and Garrick and Gray [37] reported their values in the range from $426 \mathrm{~K}$ to $527 \mathrm{~K}$. The absolute average deviation (AAD) between the reported values were $0.4 \%$ and $0.3 \%$, respectively. Therefore, good agreement was obtained for a wide range of experimental pressures. 


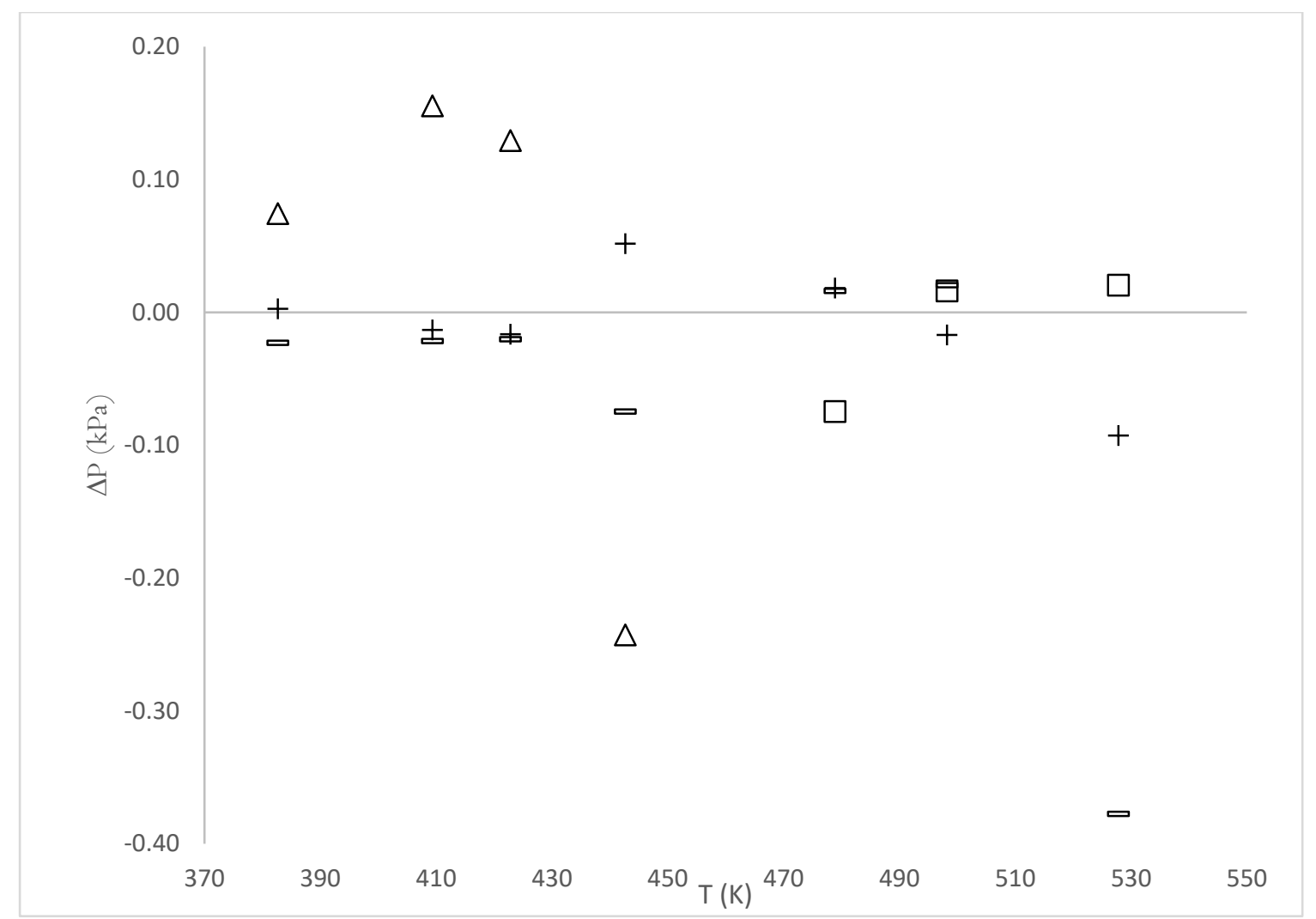

Figure 2. Deviation plot for vapor pressures of biphenyl: + from DSC experimental data, - from Chirico et. al [35], $\square$ Chipman and Peltier from [36], $\square$ Garrick and Gray from [37]

$\Delta P$ value Calculated using the formula $\Delta P \%=\frac{P_{l i t}-P_{e}}{P_{e}} \times 100$ where $\mathrm{P}_{\text {lit }}$ is the vapor pressure obtained from literature and $\mathrm{P}_{\mathrm{e}}$ is calculated from the Antoine equation fit to the experimental vapor pressure data measured in this work

\subsection{PC-SAFT optimization}

The properties of 4-ethyl-2-methoxyphenol were modelled using the PC-SAFT equation of state [41], and therefore, vapor pressure curves were fit to the experimental data using the PCSAFT equation of state. The PC-SAFT parameters were determined using the differential evolution optimizer implemented in the Scipy package for Python [42] [43]. Our PC-SAFT code can be found on Github [44] and is also available as a package on the Python Package Index [45]. The vapor pressure and density data were used for optimization. Because there was no available density data for the solid compounds (5-methylresorcinol and Honeyol $^{\mathrm{TM}}$ ), PCSAFT parameters were not optimized. 


\subsection{Uncertainty analysis}

For uncertainty calculations a coverage factor of $2(\mathrm{k}=2)$ was used. The estimated expanded uncertainty of the temperature measurement was $0.25 \mathrm{~K}[6]$. For pressure measurement uncertainty, the expanded uncertainty was determined based on data from the performance check with water. Based on the deviation between measured values and the IAPWS95 equation of state [33], the expanded uncertainty of vapor pressures measured using the device was $1.4 \%$. Because the pressure sensor has a resolution of 0.01 torr $(0.001 \mathrm{kPa})$, for measurements at low pressures a minimum expanded uncertainty of $0.07 \mathrm{kPa}$ was assumed. The effect of impurities was also included for pressure uncertainty calculations. This was calculated by estimating the likely relative deviation of the vapor pressures of the impurities and multiplying that by the concentration of the impurities (i.e. ideal mixing was assumed). For 5-methylresorcinol, the impurity concentration was negligible, and therefore was not considered.

\section{Results and discussion}

The Table 6 provides the density values for 4-ethyl-2-methoxyphenol at 20 to $90{ }^{\circ} \mathrm{C}$ and The PC-SAFT parameters for 4-ethyl-2-methoxyphenol are given in Table 7.

Table 6. 4-ethyl-2-methoxyphenol density values from 20 to $90^{\circ} \mathrm{C}$.

$\begin{array}{cc}\begin{array}{c}\text { Temperature } \\ {\left[{ }^{\circ} \mathbf{C}\right]}\end{array} & \begin{array}{c}\text { Density }^{\mathrm{b}} \\ {\left[\mathbf{g} / \mathbf{c m}^{3}\right]}\end{array} \\ 20 & 1.064 \\ 30 & 1.055 \\ 40 & 1.046 \\ 50 & 1.037 \\ 60 & 1.028 \\ 70 & 1.018 \\ 80 & 1.009 \\ 90 & 1.000\end{array}$

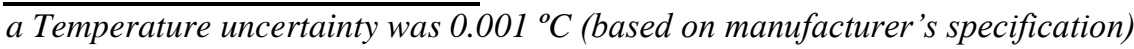

$b$ Expanded uncertainty $(k=2)$ was $0.001 \mathrm{~g} \mathrm{~cm}^{-3}$ 
Table 7. 4-ethyl-2-methoxyphenol PC-SAFT parameters.

\begin{tabular}{cccccc}
\hline Fraction & $\mathbf{m}$ & $\boldsymbol{\sigma}$ & $\mathbf{\epsilon} / \mathbf{k}$ & $\mathbf{\epsilon}^{\mathbf{A B} / \mathbf{k}}$ & $\mathbf{k}^{\mathbf{A B}}$ \\
\hline $\begin{array}{c}\text { 4-ethyl-2 } \\
\text { methoxyphenol }\end{array}$ & 4.7776 & 3.4799 & 284.44 & 1004.12 & 0.0266
\end{tabular}

Vapor pressure data for 4-ethyl-2-methoxyphenol, Honeyol ${ }^{\mathrm{TM}}$, and 5-methylresorcinol were measured within pressure range of $0.89 \mathrm{kPa}$ to atmospheric pressure using DSC.

Table 8. Experimental vapor pressure data of the measured phenolic compounds.

\begin{tabular}{|c|c|c|c|c|c|}
\hline \multicolumn{2}{|c|}{ 4-ethyl-2-methoxyphenol } & \multicolumn{2}{|c|}{ 5-methylresorcinol } & \multicolumn{2}{|c|}{ Honeyol $^{\mathrm{TM}}$} \\
\hline $\mathbf{T}[\mathbf{K}]^{\mathrm{a}}$ & $\mathbf{P}[\mathbf{k P a}]^{\mathrm{c}}$ & $\mathbf{T}[\mathbf{K}]^{\mathrm{a}}$ & $\mathbf{P}[\mathbf{k P a}]^{\mathrm{b}}$ & $\mathbf{T}[\mathbf{K}]^{\mathrm{a}}$ & $\mathbf{P}[\mathbf{k P a}]^{\mathrm{b}}$ \\
\hline 374.5 & 0.90 & 429.4 & 0.91 & 428.0 & 0.91 \\
\hline 412.0 & 4.92 & 467.8 & 4.93 & 466.6 & 4.93 \\
\hline 430.1 & 9.91 & 486.3 & 9.90 & 485.4 & 9.90 \\
\hline 473.6 & 39.88 & 530.4 & 39.85 & 529.5 & 39.88 \\
\hline 494.5 & 69.87 & 551.0 & 69.91 & 550.6 & 69.89 \\
\hline 509.1 & 100.01 & 565.8 & 100.37 & 565.0 & 99.69 \\
\hline
\end{tabular}

a Combined expanded uncertainty ( $k=2$ ) for temperature is $U(T)=0.25 \mathrm{~K}$

$b$ Combined expanded uncertainty $(k=2)$ for pressure is $U(P)=1.4 \%$ of the pressure value or $U(P)=0.07 k P a$, whichever is greater.

c Combined expanded uncertainty $(k=2)$ for the vapor pressure of 4-ethyl-2-methoxyphenol is 1.6\%, except for $0.9 \mathrm{kPa}$ experiment where the expanded uncertainty is $7.8 \%$ 


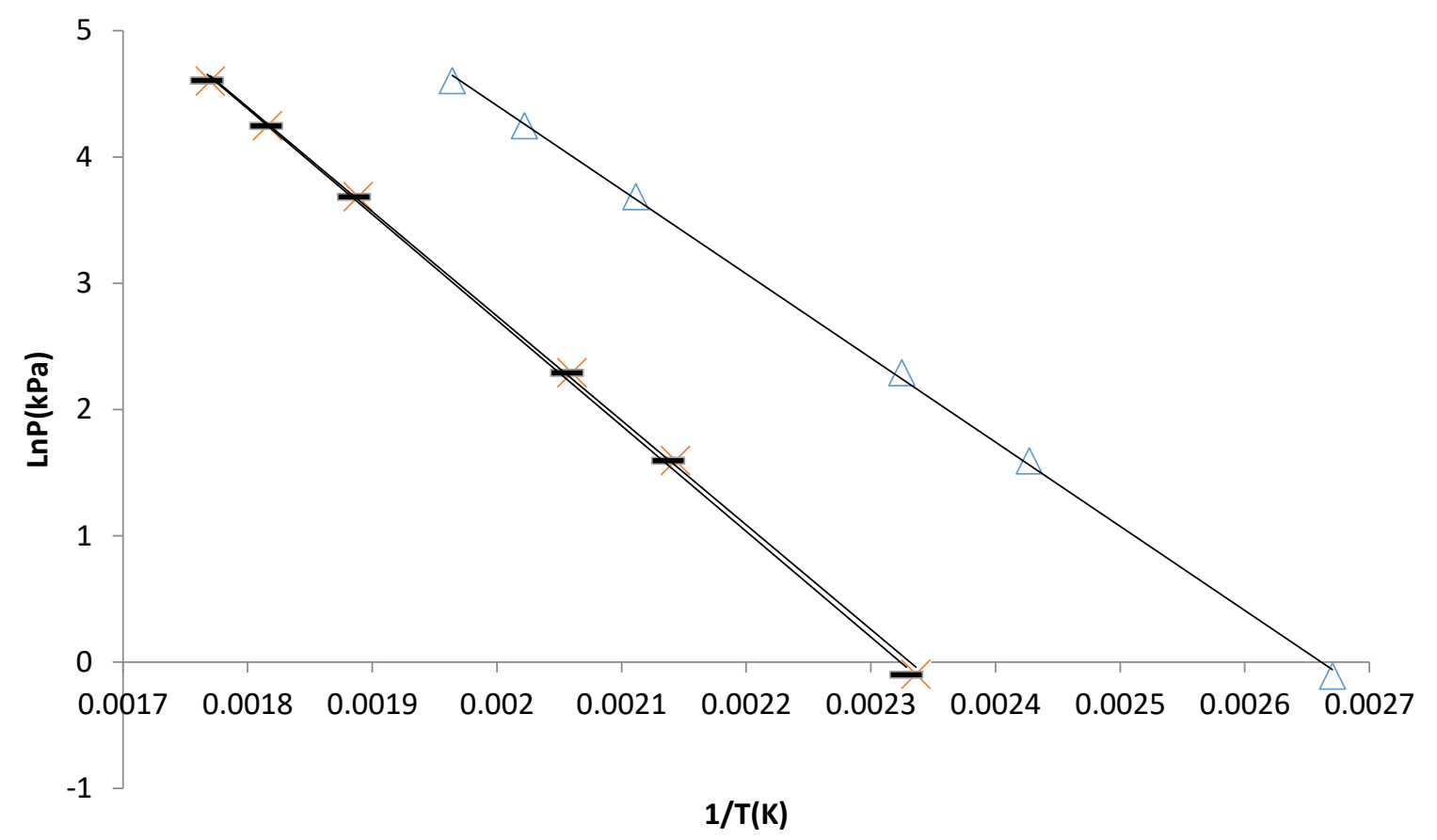

Figure 3. Vapor pressure curves for phenolic compounds measured by DSC: Honeyol ${ }^{T M}\left(\times R^{2}=0.9994\right), 4$ ethyl-2-methoxyphenol $\left(\square R^{2}=0.9995\right)$, 5-methylresorcinol $\left(-R^{2}=0.9994\right)$.

Experimental vapor pressure data for these compounds are provided in Table 8 and plotted in Figure 3. Vapor pressure curves were fit using the Antoine equation (Equation 7).

$$
\log _{10} \mathrm{P}=\mathrm{A}-\frac{\mathrm{B}}{\mathrm{T}+\mathrm{C}}
$$

Where $\mathrm{P}$ is the vapor pressure $(\mathrm{kPa}), \mathrm{T}$ is the temperature $\left({ }^{\circ} \mathrm{C}\right)$ and $\mathrm{A}, \mathrm{B}$ and $\mathrm{C}$ are Antoine equation constants. To estimate the Antoine coefficients, along with $95 \%$ confidence intervals, POLYMATH software (version 6.1) was used.

The enthalpy of vaporization $\left(\Delta \mathrm{H}_{\text {vap }}\right)$ at the normal boiling point was calculated from the slope of the linear Clausisus-Clapyeron equation. Therefore, from the $\ln \mathrm{P}$ vs $1 / \mathrm{T}$ plot:

$\frac{d(\ln P)}{d\left(\frac{1}{T}\right)}=\frac{\Delta H_{v a p}}{R}$

Where, $\Delta \mathrm{H}_{\text {vap }}$ is the enthalpy of vaporization $\left(\mathrm{kJ} \mathrm{mol}^{-1}\right)$ and $\mathrm{R}$ is the universal gas constant $(\mathrm{R}$ $=8.314 \mathrm{~J} \mathrm{~mol}^{-1} \mathrm{~K}^{-1}$ ). Although vapor pressures were experimentally obtained at atmospheric conditions, the normal boiling points of the compounds $(\mathrm{P}=101.325 \mathrm{kPa})$ were calculated from the vapor pressure curves. 
Melting points of the solid compounds were obtained from the onset temperature of the melting peak of the thermoanalytical curve. For 5-methylresorcinol, the average of repeat measurements was calculated and is provided in Table 9. For Honeyol ${ }^{\mathrm{TM}}$ the melting range is given instead of a melting point because it is a mixture. Because the melting peak of Honeyol ${ }^{\mathrm{TM}}$ was small and broad, the melting temperature was estimated from the peak.

It should be noted that the composition of Honeyol ${ }^{\mathrm{TM}}$ varies, as seen from comparing with the compositions in other articles [46], [47]. However, the properties of Honeyol ${ }^{\mathrm{TM}}$, such as vapor pressures values, boiling points and melting points, are very similar to those of 5methylresorcinol. Therefore, the presence of other resorcinols derivatives does not significantly affect the properties of $\mathrm{Honeyol}^{\mathrm{TM}}$ in general, likely because the different resorcinols have quite similar structures.

The experimental temperature range, Antoine parameters obtained from Equation 8, boiling point at $101.325 \mathrm{kPa}$ and vaporization enthalpy of the studied compounds, along with expanded uncertainties $(\mathrm{k}=2)$, are given in Table 9.

Table 9. Experimental temperature ranges, Antoine constants, enthalpies of vaporization and melting points for the phenolic compounds.

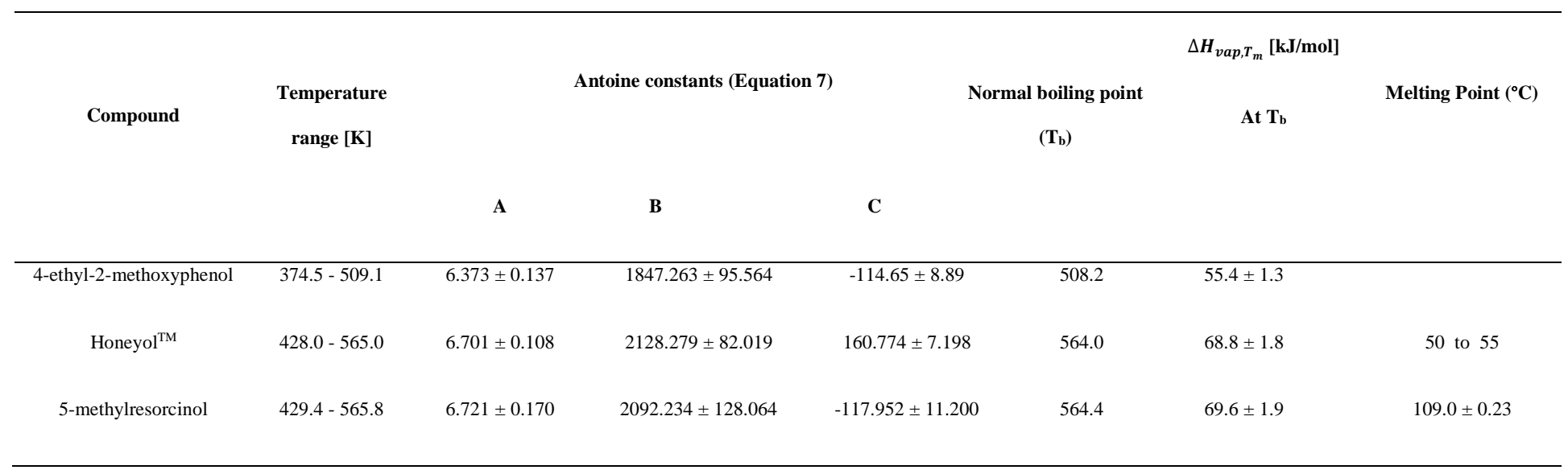

For the compounds measured, only a few scattered data are available in the literature for comparison. Based on the literature from Weast and Graselli [48], the normal boiling point of 5-methylresorcinol is $562.7 \mathrm{~K}$, which is $1.7 \mathrm{~K}$ lower than the value from our vapor pressure curve (relative deviation within $0.3 \%$ ). 


\section{Comparison with boiling points of phenolic fractions}

Phenols are one of the main classes of compounds in Kukersite shale oil [6]. Furthermore, Phenolic compounds are one of the main classes of organic components of bio oils, produced from woods, which comprises about 20-30\% [49].

The normal boiling points (normal $\mathrm{T}_{\mathrm{b}}$ ) of the phenolic compounds studied in this article were compared with those of other phenolic compounds obtained from [50] and the characteristics of phenolic shale oil fractions measured earlier by our research group, (this data will be published soon in another article). The phenolic fractions were prepared from the shale oil using the method suggested by Kogerman [51] and described in [5], [52].

For the purpose of the analysis, fractions with normal boiling points below $620 \mathrm{~K}$, phenolic compounds with two hydroxyl groups [6] and three isomeric methylphenols (cresol) [53] were considered for comparison.

Molecular weights and normal boiling points of disubsituted phenolic compounds (containing two hydroxyl groups) were obtained from [6]. Properties of other phenolic compounds were obtained from elsewhere [50]. The other phenolic compounds include six dimethylphenol isomers (xylenol), two trimethylphenol isomers, two ethylphenol isomers, catechol and 4propylphenol.

Figure 4 presents the normal boiling points of different phenolic compounds as a function of their molecular weight. Based on the number of $\mathrm{OH}$ groups per molecule, phenolic shale oil fractions were divided into three categories. Fractions with fewer $\mathrm{OH}$ groups per molecule (below 0.64 ), fractions with a higher $\mathrm{OH}$ content ( 0.64 to $1.30 \mathrm{OH}$ groups per molecule), and a third group with the most $\mathrm{OH}$ groups ( $>1.30$ per molecule). For the fractions with higher $\mathrm{OH}$ contents, clearly some molecules have more than one $\mathrm{OH}$ group. 


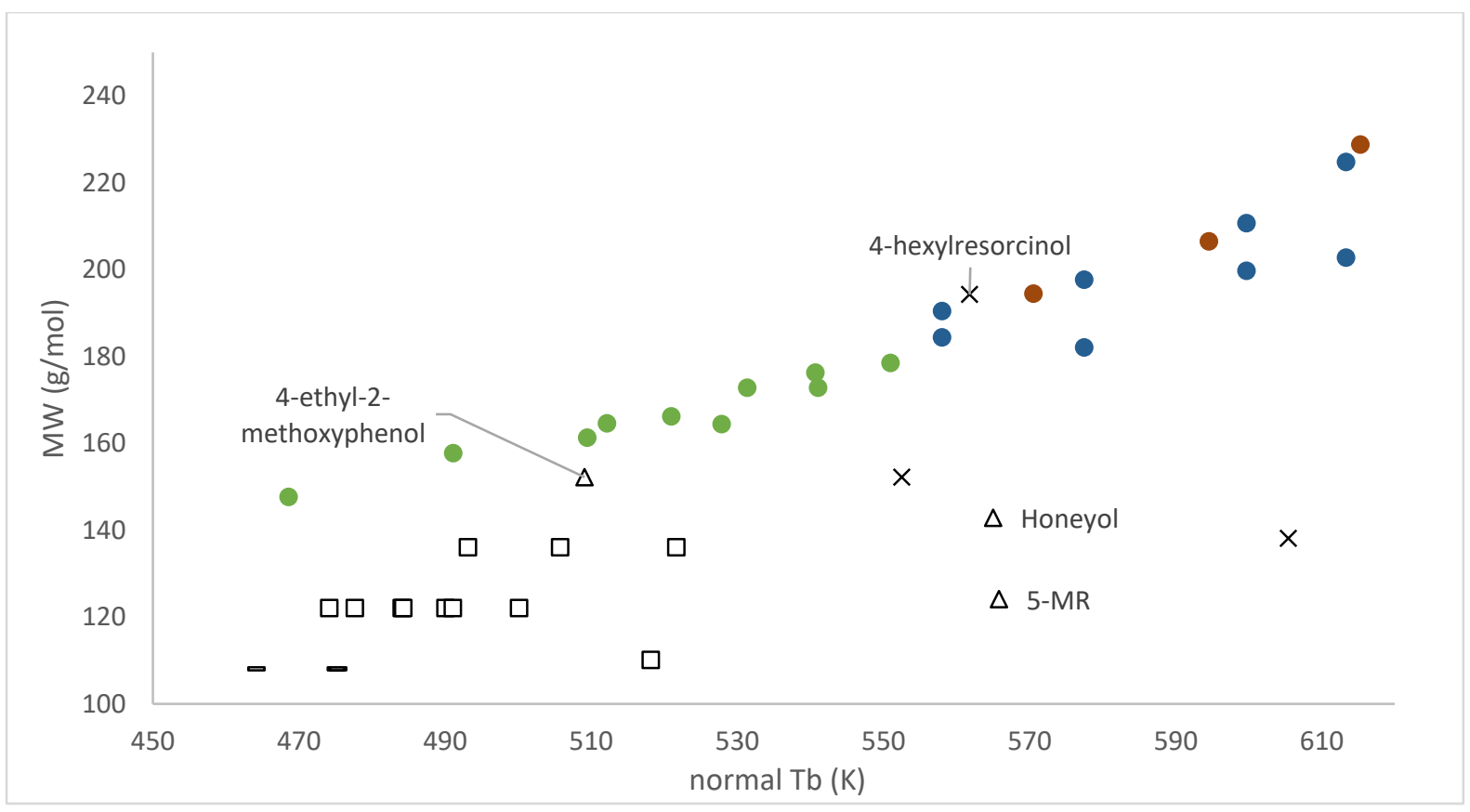

Figure 4. Comparison of the properties of various phenolic compounds. Phenolic oil fractions - 0.1-0.64 OH per molecule $\left(^{\bullet}\right)$ [54] Phenolic oil fractions - 0.64-1.30 OH per molecule (•) [54], . Phenolic fractions $->1.30 \mathrm{OH}$

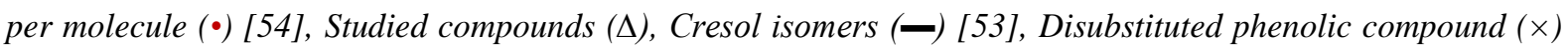
[6], Other phenolic compounds ( $\square$ ) [50].

The $\mathrm{OH}$ content of the phenolic oil fractions were determined from the infrared spectra of the phenolic fractions [5]. .

The normal boiling point of 4-ethyl-2-methoxyphenol was measured to be $508.2 \mathrm{~K}$. Two fractions had similar normal boiling points (normal $\mathrm{T}_{\mathrm{b}}=509.5$ and $\mathrm{MW}=161.3 \mathrm{~g} / \mathrm{mol}, \mathrm{T}_{\mathrm{b}}=$ $512.2 \mathrm{~K}$ and $\mathrm{MW}=164.6 \mathrm{~g} / \mathrm{mol}$ ) and could be directly compared. The $\mathrm{OH}$ contents of these fractions were measured to be 3.4 and $4.0 \mathrm{wt} \%$, and their densities at $20{ }^{\circ} \mathrm{C}\left(\mathrm{d}_{20}\right)$ were 0.907 $\mathrm{g} / \mathrm{cm}^{3}$ and $0.924 \mathrm{~g} / \mathrm{cm}^{3}$, respectively. Despite having slightly lower densities than 4-ethyl-2methoxyphenol $\left(\mathrm{d}_{20}=1.064 \mathrm{~g} / \mathrm{cm}^{3}\right)$ these fractions have higher molecular weights. Furthermore, as shown in Figure 1, 4-ethyl-2-methoxyphenol also contains one methoxy group $\left(-\mathrm{OCH}_{3}\right)$ and one methyl group $\left(-\mathrm{CH}_{3}\right)$. However, $\mathrm{OH}$ analysis of these fractions indicates that on average molecules in these oil samples had less than one $\mathrm{OH}$ group per molecule, so some of the molecules were not phenolic compounds. 4-hexylresorcinol is also in neighborhood of some phenolic fractions for which the normal boiling points and molecular weights are near $562 \mathrm{~K}$ and $195 \mathrm{~g} / \mathrm{mol}$. The 4-hexylresorcinol structure contains one $\mathrm{OH}$ group and one long hydrocarbon chain attached to the phenol unit.

Overall, as shown in Figure 4, compounds 4-ethyl-2-methoxyphenol and 4-hexylresorcinol behave similar to the phenolic fractions, and therefore, are in line with the trend of phenolic 
fractions. These compounds have longer hydrocarbon side chains in their molecular structure (-OCH 3 chain for 4-ethyl-2-methoxyphenol and $-\mathrm{CH}_{3}\left(\mathrm{CH}_{2}\right)_{4} \mathrm{CH}_{2}$ chain for 4-hexylresorcinol) compared with the other phenolic compounds considered here. Also, 4-ethyl-2-methoxyphenol has only one hydroxyl group. Most of the oil fractions shown here also had closer to $1 \mathrm{OH}$ group per molecule, and therefore, 4-ethyl-2-methoxyphenol could likely behave similarly to phenolic fractions.

Other compounds used in this study, as well as other phenolic compounds that contained one phenol unit, differed more from the properties of the phenolic oil fractions, and therefore, these compounds would probably not be as useful for modelling the phenolic compounds in pyrolysis oil.

\section{Conclusions}

Differential scanning calorimetry (DSC) was used to measure the vapor pressures of the phenolic compounds 4-ethyl-2-methoxyphenol, $\mathrm{Honeyol}^{\mathrm{TM}}$, and 5-methylresorcinol from $0.89 \mathrm{kPa}$ to atmospheric pressure. To our knowledge, these are the first published vapor pressure curves for Honeyol $^{\mathrm{TM}}$ and 4-ethyl-2-methoxyphenol, and the first vapor pressure data for 5-methylresorcinol in this pressure range. The normal boiling points and heats of vaporization of the phenolic compounds were calculated using the obtained vapor pressure curves. Also, properties of these and other pure phenolic compounds were compared to those of the phenolic portion of pyrolysis oil (Kukersite shale oil). This allowed us to identify the compounds that could potentially be used as model compounds for predicting the behavior of pyrolysis oil. While, 4-ethyl-2-methoxyphenol could likely be used as a model compound, 5-methylresorcinol and Honeyol $^{\mathrm{TM}}$ did not appear to be as useful for modelling oil.

\section{Bibliography}

[1] M. Kiliç, A. E. Pütün, B. B. Uzun, and E. Pütün, "Converting of oil shale and biomass into liquid hydrocarbons via pyrolysis," Energy Convers. Manag., 2014, doi: 10.1016/j.enconman.2013.11.002.

[2] V. Oja and E. M. Suuberg, "Oil Shale oil shale Processing oil shale processing, Chemistry and Technology," in Encyclopedia of Sustainability Science and Technology, 2012.

[3] N. Savest, V. Oja, T. Kaevand, and Ü. Lille, "Interaction of Estonian kukersite with organic solvents: A volumetric swelling and molecular simulation study," Fuel, vol. 86, no. 1-2, pp. 17-21, Jan. 2007, doi: 10.1016/j.fuel.2006.06.016. 
[4] B. P. Tissot, D. H. Welte, B. P. Tissot, and D. H. Welte, "Oil Shales: A Kerogen-Rich Sediment with Potential Economic Value," in Petroleum Formation and Occurrence, Springer Berlin Heidelberg, 1978, pp. 225-236.

[5] Z. S. Baird, V. Oja, and O. Järvik, "Distribution of hydroxyl groups in kukersite shale oil: Quantitative determination using fourier transform infrared (FT-IR) spectroscopy," Appl. Spectrosc., 2015, doi: 10.1366/14-07705.

[6] H. L. Astra and V. Oja, "Vapour pressure data for 2-n-propylresorcinol, 4ethylresorcinol and 4-hexylresorcinol near their normal boiling points measured by differential scanning calorimetry," J. Chem. Thermodyn., 2019, doi: 10.1016/j.jct.2019.03.008.

[7] V. Oja, "Vaporization parameters of primary pyrolysis oil from kukersite oil shale," Oil Shale, vol. 32, no. 2, pp. 124-133, 2015, doi: 10.3176/oil.2015.2.03.

[8] A. Effendi, H. Gerhauser, and A. V. Bridgwater, "Production of renewable phenolic resins by thermochemical conversion of biomass: A review," Renewable and Sustainable Energy Reviews, vol. 12, no. 8. Pergamon, pp. 2092-2116, Oct. 01, 2008, doi: 10.1016/j.rser.2007.04.008.

[9] S. Xiu and A. Shahbazi, "Bio-oil production and upgrading research: A review," Renewable and Sustainable Energy Reviews, vol. 16, no. 7. pp. 4406-4414, Sep. 2012, doi: 10.1016/j.rser.2012.04.028.

[10] Wahyudiono, M. Sasaki, and M. Goto, "Recovery of phenolic compounds through the decomposition of lignin in near and supercritical water," Chem. Eng. Process. Process Intensif., vol. 47, no. 9-10, pp. 1609-1619, Sep. 2008, doi: 10.1016/j.cep.2007.09.001.

[11] J. Schuler, U. Hornung, A. Kruse, N. Dahmen, and J. Sauer, "Hydrothermal Liquefaction of Lignin,” J. Biomater. Nanobiotechnol., vol. 08, no. 01, pp. 96-108, 2017, doi: 10.4236/jbnb.2017.81007.

[12] Y. Ye, Y. Zhang, J. Fan, and J. Chang, "Selective production of 4-ethylphenolics from lignin via mild hydrogenolysis," Bioresour. Technol., vol. 118, pp. 648-651, Aug. 2012, doi: 10.1016/j.biortech.2012.05.127.

[13] Y. Yang, A. Gilbert, and C. (Charles) Xu, "Hydrodeoxygenation of bio-crude in supercritical hexane with sulfided CoMo and CoMoP catalysts supported on MgO: A model compound study using phenol," Appl. Catal. A Gen., vol. 360, no. 2, pp. 242249, Jun. 2009, doi: 10.1016/j.apcata.2009.03.027.

[14] X. Zhang, Q. Zhang, T. Wang, L. Ma, Y. Yu, and L. Chen, "Hydrodeoxygenation of lignin-derived phenolic compounds to hydrocarbons over $\mathrm{Ni} / \mathrm{SiO} 2-\mathrm{ZrO} 2$ catalysts," 
Bioresour. Technol., vol. 134, pp. 73-80, Apr. 2013, doi:

10.1016/j.biortech.2013.02.039.

[15] G. Lyu, S. Wu, and H. Zhang, "Estimation and comparison of bio-oil components from different pyrolysis conditions," Front. Energy Res., vol. 3, no. JUN, 2015, doi: 10.3389/fenrg.2015.00028.

[16] J. G. Speight, Handbook of petrochemical processes. CRC Press, 2019.

[17] G. Jinsheng, Ed., Coal, Oil Shale, Natural Bitumen, Heavy Oil and Peat-Volume II. EOLSS Publications, 2009.

[18] O. Järvik, R. Rannaveski, E. Roo, and V. Oja, "Evaluation of vapor pressures of 5Methylresorcinol derivatives by thermogravimetric analysis," Thermochim. Acta, 2014, doi: 10.1016/j.tca.2014.07.001.

[19] Z. S. Baird, P. Uusi-Kyyny, O. Järvik, V. Oja, and V. Alopaeus, "Temperature and Pressure Dependence of Density of a Shale Oil and Derived Thermodynamic Properties," Ind. Eng. Chem. Res., vol. 57, no. 14, pp. 5128-5135, Apr. 2018, doi: 10.1021/acs.iecr.7b05018.

[20] H. Pichler and J. Lutz, "Why Crude Oil Vapor Pressure Should Be Tested Prior to Rail Transport," Adv. Pet. Explor. Dev., vol. 7, no. 2, pp. 58-63, 2014, doi: 10.3968/5098.

[21] C. Siitsman and V. Oja, "Extension of the DSC method to measuring vapor pressures of narrow boiling range oil cuts," Thermochim. Acta, 2015, doi: 10.1016/j.tca.2015.04.011.

[22] J. Phillips, “The structure and reaction processes of coal. By K. L. Smith, L. D. Smoot, T. H. Fletcher, and R. J. Pugmire, Plenum Press, New York, 1994, 471 pp.,\$75.00,” AIChE J., vol. 42, no. 8, pp. 2399-2400, Aug. 1996, doi: 10.1002/aic.690420834.

[23] M. A. V. Ribeiro da Silva and A. I. M. C. Lobo Ferreira, "Experimental standard molar enthalpies of formation of some methylbenzenediol isomers," J. Chem. Thermodyn., vol. 41, no. 10, pp. 1096-1103, Oct. 2009, doi: 10.1016/j.jct.2009.04.015.

[24] R. J. Seyler, "Parameters affecting the determination of vapor pressure by differential thermal methods," Thermochim. Acta, vol. 17, no. 2, pp. 129-136, Nov. 1976, doi: 10.1016/0040-6031(76)85019-8.

[25] K. Jones and R. Seyler, "Differential Scanning Calorimetry for Boiling Points and Vapor Pressure."

[26] D. Tilinski and H. Puderbach, "Experiences with the use of DSC in the determination of vapor pressure of organic compounds," J. Therm. Anal., 1989, doi: 10.1007/BF01904452. 
[27] American Society for Testing and Materials Method E 1782-03, "Standard Test Method for Determining Vapor Pressure by Thermal Analysis.” ASTM International, West Conshohocken, PA.

[28] O. Järvik and V. Oja, "Molecular weight distributions and average molecular weights of pyrolysis oils from oil shales: Literature data and measurements by SEC and ASAP MS for oils from four different deposits," Energy \& Fuels, 2016, doi:

10.1021/acs.energyfuels.6b02452.

[29] C. Siitsman, I. Kamenev, and V. Oja, "Vapor pressure data of nicotine, anabasine and cotinine using differential scanning calorimetry," Thermochim. Acta, 2014, doi: 10.1016/j.tca.2014.08.033.

[30] C. Siitsman and V. Oja, "Application of a DSC based vapor pressure method for examining the extent of ideality in associating binary mixtures with narrow boiling range oil cuts as a mixture component," Thermochim. Acta, 2016, doi: 10.1016/j.tca.2016.05.011.

[31] A. Brozena, "Vapor pressure of 1-octanol below $5 \mathrm{kPa}$ using DSC," Thermochim. Acta, 2013, doi: 10.1016/j.tca.2013.03.018.

[32] A. B. Butrow and R. J. Seyler, "Vapor pressure by DSC: Extending ASTM E 1782 below 5 kPa," Thermochim. Acta, 2003, doi: 10.1016/s0040-6031(02)00604-4.

[33] W. Wagner and A. Pruß, "The IAPWS formulation 1995 for the thermodynamic properties of ordinary water substance for general and scientific use," J. Phys. Chem. Ref. Data, 2002, doi: 10.1063/1.1461829.

[34] I. H. Bell, J. Wronski, S. Quoilin, and V. Lemort, "Pure and pseudo-pure fluid thermophysical property evaluation and the open-source thermophysical property library coolprop," Ind. Eng. Chem. Res., 2014, doi: 10.1021/ie4033999.

[35] R. D. Chirico, S. E. Knipmeyer, A. Nguyen, and W. V. Steele, "The thermodynamic properties of biphenyl," J. Chem. Thermodyn., 1989, doi: 10.1016/00219614(89)90119-5.

[36] J. Chipman and S. B. Peltier, "Vapor Pressure and Heat of Vaporization of Diphenyl," Ind. Eng. Chem., vol. 21, no. 11, pp. 1106-1108, Nov. 1929, doi: 10.1021/ie50239a034.

[37] F. J. Garrick, "The vapour pressures of diphenyl and of aniline," Trans. Faraday Soc., vol. 23, no. 0, pp. 560-563, Jan. 1927, doi: 10.1039/tf9272300560.

[38] K. Sasse, J. N'guimbi, J. Jose, and J. C. Merlin, “Tension de vapeur d'hydrocarbures polyaromatiques dans le domaine 10-3-10 Torr," Thermochim. Acta, vol. 146, no. C, 
pp. 53-61, Jun. 1989, doi: 10.1016/0040-6031(89)87075-3.

[39] R. S. Bradley and T. G. Cleasby, "The vapour pressure and lattice energy of some aromatic ring compounds," J. Chem. Soc., vol. 0, no. 0, pp. 1690-1692, Jan. 1953, doi: 10.1039/jr9530001690.

[40] S. Seki and K. Suzuki, "Physico-Chemical Studies on Molecular Compounds. III. Vapor Pressures of Diphenyl, 4, 4'-Dinitrodiphenyl, and Molecular Compound between Them," Bull. Chem. Soc. Jpn., vol. 26, no. 5, pp. 209-213, May 1953, doi: 10.1246/bcsj.26.209.

[41] J. Gross and G. Sadowski, "Perturbed-chain SAFT: An equation of state based on a perturbation theory for chain molecules," Ind. Eng. Chem. Res., 2001, doi: 10.1021/ie0003887.

[42] S. R and P. K, "Differential Evolution - A Simple and Efficient Heuristic for Global Optimization over Continuous Spaces,” J. Glob. Optim., 1997, doi: 10.1071/AP09004.

[43] E. Jones, T. Oliphant, and P. Peterson, "SciPy: Open source scientific tools for Python,” 2001, Accessed: Jun. 17, 2020. [Online]. Available: https://www.scienceopen.com/document?vid=ab12905a-8a5b-43d8-a2bbdefc771410b9.

[44] Z. S. Baird, "pcsaft: The PC-SAFT equation of state; including dipole; association and ion terms.; n.d.”.

[45] PyPI, "PyPI - the Python Package Index." .

[46] A. L. Peikolainen, F. Pérez-Caballero, and M. Koel, "Low-density organic aerogels from oil shale by-product 5-methylresorcinol," Oil Shale, vol. 25, no. 3, 2008, doi: 10.3176/oil.2008.3.06.

[47] K. Siimer, T. Kaljuvee, P. Christjanson, T. Pehk, and I. Saks, "Effect of alkylresorcinols on curing behaviour of phenol-formaldehyde resol resin," J. Therm. Anal. Calorim., vol. 91, no. 2, 2008, doi: 10.1007/s10973-007-8449-1.

[48] R. C. Weast, J. G. Grasselli, and D. R. Lide, Handbook of data on organic compounds. CRC Press, 1989.

[49] M. S., A. L. B. D. Santana, C. A., L. S., and L. Bieber, "Phenolic Extractives and Natural Resistance of Wood," in Biodegradation - Life of Science, 2013.

[50] D. R. Lide, Ed., CRC handbook of chemistry and physics, 85th ed. CRC Press, 2004.

[51] P. N. Kogerman, "On the chemistry of the Estonian oil shale "Kukersite“," 1931.

[52] Z. S. Baird, "Predicting Fuel Properties from Infrared Spectra," 2017.

[53] D. P. Biddiscombe and J. F. Martin, "VAPOUR PRESSURES OF PHENOL AND 
THE CRESOLS,” 1958.

[54] O. Järvik, Z. S. Baird, R. Rannaveski, and V. Oja, "Properties of kukersite shale oil. Part 1: Experimental data," 2020. 